\title{
LA «EXCEPTIO NON ADIMPLETI CONTRACTUS»
}

\author{
José Manuel Fernández Hierro
}

Sumario: 1. Antecedentes. 2. Normativas aplicables. 3. Concepto y clases. 4. Excepción y derecho de retención. 5. Exceptio y compensación. 6. Exceptio y resolución contractual. 7. Condiciones. 8. Ejercicio de la exceptio. 9. La exceptio non adimpleti contractus y la letra de cambio.

La «exceptio non adimpleti contractus» y su variante la «exceptio non rite adimpleti contractus» son utilizadas con frecuencia en la praxis jurídica.

\section{Antecedentes}

A pesar de su denominación el derecho romano no conoció la excepción non adimpleti contractus, sino que fueron los canonistas y los glosadores los que la crearon como medio de defensa del deudor en los contratos sinalagmáticos, fundamentándose, sobre todo los primeros, que realmente la iniciaron, en la no legitimación de quien ha incumplido el contrato para pedir el cumplimiento del otro contratante, porque las obligaciones debían ejecutarse simultáneamente por ambas partes.

Conceptualmente se ha discutido sobre si su fundamentación técnica puede ser una condición suspensiva, una condición resolutoria, un pacto de non petendo o un término inicial para la exigencia del cumplimiento de la obligación ${ }^{1}$.

1 Espín CÁNOVAS, «La excepción de cumplimiento contractual», en Anuario de Derecho Civil, julio-septiembre 1964, pp. 557 y ss. 
Todas estas construcciones tienen sus inconvenientes y así, se ha objetado con acierto que la teoría de la condición suspensiva conduce al círculo vicioso en el que nunca se sabe cuándo existen las obligaciones recíprocas, puesto que la condición para el nacimiento de cada una es la realización de la contraria ${ }^{2}$.

La excepción comentada se generalizó en el derecho antiguo; pero lo que es más notable constatar es que sin haber sido como tal reconocida por los ordenamientos modernos, se siga aplicando por los tribunales en diferentes países, entre ellos en España.

Su regulación y configuración ha sido una tarea evidentemente jurisprudencial, y será a ésta a donde haya que atender para fijar los contornos de la excepción comentada, tanto más cuando la doctrina no ha prestado excesiva atención a la misma.

El propio Tribunal Supremo así lo ha recogido en su sentencia de 30 de enero de $1987^{3}$ :

«... excepción que, no obstante la falta de regulación expresa en nuestro Ordenamiento, viene siendo reconocida por la doctrina científica y sancionada por este Tribunal con apoyo en los artículos 1.100 — párrafo último-y 1.124 del Código civil, a cuyo amparo la jurisprudencia no ha dudado en admitir tanto la exceptio de "non adimpleti contractus" como la denominada, con la misma base de respeto a lo prometido y a la buena fe, de "non rite adimpleti contractus" - SS. 5 julio 1946; 22 marzo 1950; 4 noviembre 1963; 12 marzo 1965; 31 diciembre 1971; 3 y 14 marzo 1973; 28 febrero 1974; 9 y 17 abril 1976; 26 octubre 1978 entre otras-.»

La doctrina francesa, antes de la publicación del Código civil, había entendido que existía implícitamente en las obligaciones del modo que luego va a recogerse indirectamente en los Códigos civiles ${ }^{4}$.

\section{Normativas aplicables}

Como queda dicho, la exceptio non adimpleti contractus no se recoge como tal en la mayoría de los Códigos civiles, lo cual no significa que no existan una serie de preceptos en los que pueda apoyarse, y en que de hecho se apoya la jurisprudencia para aplicarla en la actualidad.

Fundamentándose en el carácter sinalagmático de las obligaciones recíprocas existen, en nuestro ordenamiento jurídico como en otros que

\footnotetext{
2 Ibidem.

Ar. 666.

4 Véase Pothier, Tratado de las obligaciones, Buenos Aires, 1978, pp. 424.
} 
también podemos examinar, una serie de preceptos en que puede apoyarse su ejercicio.

En Derecho francés el artículo 1.146 del Código de Napoleón indica:

«Les dommages et intérets ne sont dus que lorsque le débiteur est en demeure de remplir son obligation, excepté néanmoins lorsque la chose que le débiteur s'était obligé de donner ou de faire ne pouvait étre donnée ou faite que dans un certain temps qu'il a laissé passer.»

Y el artículo 1.184 señala:

«La condition résolutoire est toujours sousentendue dans les contrats synallagmatiques, pour le cas ou l'une des deux parties ne satisfera point a son engagement.

Dans ce cas, le contrat n'est point résolu de plein droit. La partie envers laquelle l'engagement n'a point été exécuté, a le choix ou de forcer l'autre a l'exécution de la convention lorsqu'elle est possible, ou d'en demander la résolution avec dommages et intérèts.

La résolution doit etre demandée en justice, et il peut etre accordé au défendeur un délai selon les circonstances.»

Es determinante en Derecho suizo el artículo 82 del Código de las obligaciones y contratos que puntualiza:

«Celui que poursuit l'exécution d'un contrat bilatéral doit avoir exécuté ou offrir d'exécuter sa propre obligation, a moins qu'il ne soit bénéfice d'un terme d'apres les clauses ou la nature du contrat.»

En Derecho alemán el $\S 320-I, 1 .^{a}$ del B.G.B. indica que:

«El obligado por virtud de un contrato bilateral puede negar la prestación que le incumbe hasta la efectuación de la contraprestación, a no ser que esté obligado a cumplir la prestación anticipadamente.»

El artículo 801 del Código civil portugués dice:

«Impossibilidade culposa.

1. Tornando-se impossivel a prestação por causa imputável ao devedor, é este responsável como se faltasse culposamente ao cumprimento da obrigação.

2. Tendo a obrigaçao por fonte um contrato bilateral, o credor, independentemente do direitio á indemnização, pode resolver o contrato e, se já tiver realizado a sua prestação, exigir a restitução dela por enteiro.»

El artículo 754 del mismo Código señala:

«Quando existe.

O devedor que disponha de um crédito contra o seu credor goza do Direito de retenção se, estando obrigado a entregar certa coisa, o seu cre- 
dito resultar de despesas feitas por causa dela ou de danos por ela causados.»

En nuestra legislación la clave es el artículo 1.124 del Código civil que, como es sabido, señala:

«La facultad de resolver las obligaciones se entiende implícita en las recíprocas, para el caso de que uno de los obligados no cumpliere lo que le incumbe.

El perjudicado podrá escoger entre exigir el cumplimiento o la resolución de la obligación, con el resarcimiento de daños y abono de intereses en ambos casos. También podrá pedir la resolución, aun después de haber optado por el cumplimiento, cuando éste resultare imposible.

El Tribunal decretará la resolución que se reclame, a no haber causas justificadas que le autoricen para señalar plazo.

Esto se entiende sin perjuicio de los derechos de terceros adquirentes, con arreglo a los artículos 1.295 y 1.298 y a las disposiciones de la Ley Hipotecaria.»

Dicho artículo, a los efectos comentados, puede verse complementado por el 1.101 y también por los artículos 1.466 y 1.467 de manera específica respecto de la compraventa.

El Tribunal Supremo ha efectuado en relación con el artículo 1.124, entre otras, las siguientes precisiones jurisprudenciales:

a) Que la resolución opera extrajudicialmente mediante declaración de voluntad emitida por uno de los contratantes y dirigida al otro, si no es impugnada luego en procedimiento civil o, alternativamente, por demanda judicial ${ }^{5}$.

b) Que el fundamento es el de la reciprocidad de las obligaciones, permitiendo al contratante fiel que en el supuesto de incumplimiento del otro contratante, salga del estado de incertidumbre que tal incumplimiento la produce ${ }^{6}$.

c) Ahora bien, la jurisprudencia más reciente señala que lo esencial es valorar conjuntamente las conductas contractuales de ambas partes, entendiendo que el incumplimiento se produce cuando se frustra el legítimo interés a la consecución del fin perseguido por la parte cumplidora con la firma del contrato ${ }^{7}$.

5 SS. 19 noviembre de 1984, Ar. 5.565, 14 de junio de 1988, Ar. 4.875 y 28 de febrero de 1989, Ar. 1409. En idéntico sentido en cuanto al derecho francés la exceptio no está subordinada a una demanda judicial, Crim. 27 de enero de 1970, Sem. Jur. 1970, II, 16554.

6 S. 16 de noviembre de 1956, Ar. 3.447.

7 SS. 18 de noviembre de 1983, Ar. 6.488, 28 de febrero de 1986, Ar. 862 y 30 de junio de 1987, Ar. 4.832. 
d) Que la resolución sólo puede solicitarla el que ha cumplido por su parte ${ }^{8}$.

e) Que el incumplimiento ha de ser de tal entidad que impida el fin normal del contrato ${ }^{9}$, no constituyéndolo el simple retraso ${ }^{10}$.

En los casos de compraventa supondría incumplimiento la entrega de una cosa por otra ${ }^{11}$ y la entrega de una cosa inservible ${ }^{12}$.

\section{Concepto y clases}

Podemos definir a la exceptio non adimpleti contratus como el medio de defensa del deudor, que opone a su acreedor la alegación de que él también ha incumplido el contrato, cuando en el mismo se prevén obligaciones recíprocas ${ }^{13}$.

8 SS. 21 de marzo de 1986, Ar. 1.275, 25 de octubre de 1988, Ar. 7.637 y 20 de junio de 1990, Ar. 4.799.

9 SS. 7 de octubre de 1988, Ar. 5.581 y 5 de mayo de 1989, Ar. 4.298.

10 SS. 30 de abril de 1981, Ar. 1.784, 21 de febrero de 1986, Ar. 838 y 6 de julio de 1989, Ar. 5.404.

11 S. 7 de enero de 1988, Ar. 117.

12 S. 29 de febrero de 1988, Ar. 1.310.

13 Desde el ángulo procesal la excepción es el método de oposición concedido por la Ley al demandado, encaminado a anular la acción propuesta pero que, como no niega la relación preexistente entre las partes, hace posible el ejercicio ulterior de nuevas acciones por el actor.

La doctrina tradicional (así De la PlaZA, Derecho Procesal Civil, Vol. 1, Madrid 1951, p. 374) ha entendido que la excepción se diferenciaba de los demás métodos de defensa del demandado en que, compartiendo con éstos el ser un modo de impugnar la demanda, sin embargo se diferencia en que no trata de atacar la relación jurídica considerada en su totalidad, sino la acción propuesta, por lo que no impide el ejercicio de nuevas acciones; todo ello sin tener en cuenta que, como regla general, las excepciones para que el Juez las pueda acoger en su sentencia deberán ser alegadas por la parte a las que la beneficia, requisito no necesario en las demás alegaciones de defensa. Guasp en cambio considera la excepción un simple método de defensa señalando que se encamina a anular la acción interpuesta por el actor de un modo específico que el Juez deberá estudiar y recoger en la sentencia (GuASP, Derecho Procesal Civil, Madrid 1956, p. 254).

De todas formas, tengamos en cuenta que en nuestro derecho concreto la excepción perentoria es excepción que afecta al fondo del asunto, y al menos a los elementos en que se fundamenta la pretensión del demandante, lo cual determina que si es estimada la pretensión adversa no pueda ser de nuevo puesta en juego.

¿Cabe que la excepción tenga carácter no procesal? La doctrina ha estado dividida sobre este particular: así Guasp propugna que la excepción fuera del proceso es una contradictio in terminis; pero advierte que lo que sucede es que con el nombre de excepción se han traído al proceso problemas y preocupaciones de derecho material que se pretenden insertar dentro de la cobertura procesal, por eso podría mantenerse la conclusión de que si la excepción puede mantenerse fuera del proceso nos encontraríamos con que no se 
Así lo ha recogido el Tribunal Supremo en la sentencia de 27 de marzo de $1991^{14}$ :

«Cuarto.-Acogido al ordinal 5. ${ }^{\circ}$ del artículo 1.692 de la L.E.Civ., se formula el quinto y último motivo por "infracción de la doctrina jurisprudencial sobre la excepción de incumplimiento contractual, "exceptio non adimpleti contractus", en su modalidad de cumplimiento defectuoso, "exceptio non rite adimpleti contractus", recogida, entre otras muchas, en las sentencias de esa Sala Primera del Tribunal Supremo de 18-4-79, 14-6-80 y 13-5-85". Los principios del respeto a la palabra dada y a la buena fe dieron lugar al nacimiento de dos acciones diferentes, una, de contrato no cumplido, llamada non adimpleti contratus, y otra de contrato no cumplido adecuadamente en -cantidad, calidad, manera o tiempo denominada exceptio non rite adimpleti contractus, acciones no reguladas expresamente en nuestro ordenamiento jurídico pero cuya existencia está implícitamente admitida en diversos preceptos y han sido sancionadas por la jurisprudencia: así, en cuanto a la primera, los artículos $1.466,1.500$ párrafo $2 .^{\circ}, 1.100$ y 1.124 del C. Civ. y las sentencias de 7 de octubre de 1895, 8 de junio de 1903, 9 de julio de 1904, 10 de abril de 1924, 1 de abril de 1925, 6 de noviembre de 1923 y 29 de diciembre de 1965, y respecto a la segunda los artículos 1.157, 1.100 apartado último, y 1.154, también del C.Civ. —sentencia 17 de abril de 1976-; por otra parte, como dice la sentencia de 13 de mayo de 1985, citada en el motivo, "el éxito de tal excepción de contrato no cumplido adecuadamente está condicionado a que el defecto o defectos de la obra sea de cierta importancia o transcendencia en relación con la finalidad perseguida y con la facilidad o dificultad de su subsanación, haciéndola impropia para satisfacer el interés del comitente, es claro que no puede ser alegada cuando lo mal realizado u omitido carezca de suficiente entidad en relación a lo bien ejecutado y el interés del comitente quede satisfecho con la obra entregada u ofrecida, de forma que las exigencias de la buena fe y el principio de conservación del contrato, no autoricen el ejercicio de la acción resolutoria del artículo 1.124

trata de una institución auténticamente procesal y mucho menos que no se refiere a las excepciones dilatorias y perentorias reguladas en la Ley de Enjuiciamiento Civil.

En el caso de la exceptio non adimpleti contractus comentada, parece evidente que la misma se puede desarrollar antes del procedimiento en contestación a cualquier requerimiento, no solamente judicial sino también público e incluso privado: es más, podría incluso el otro contratante aceptar el contenido del requerimiento extrajudicial en el que se alegaba la exceptio non adimpleti contractus, cumplir lo que le faltaba de su prestación y, en el ulterior procedimiento judicial dilucidarse otros extremos como, por ejemplo, el del valor de las mejoras producidas en el objeto de la compraventa.

Por todo ello es claro, en mi opinión, el carácter extraprocesal de la institución comentada.

14 Ar. 2.451. 
del citado texto sustantivo y sólo permitan la vía reparatoria, bien mediante la realización de las operaciones correctoras precisas, bien a través de la consiguiente reducción del precio — sentencias de 21 de noviembre de 1971, 17 de enero de 1975, de 15 de marzo y de 3 de octubre de 1979_-"; no habiéndose ejercitado por los demandados acción reconvencional sino alegada exclusivamente la excepción de contrato no cumplido adecuadamente con la finalidad de retrasar el pago de la cantidad reclamada, es clara su improcedencia a tenor de la citada doctrina jurisprudencial, dada la finalidad meramente reparatoria, por cualquiera de los medios indicados, de la alegada excepción; en consecuencia procede desestimar el motivo.»

Se distinguen dos clases de excepciones paralelas: la exceptio non adimpleti contractus y la exceptio non rite adimpleti contractus.

La diferencia entre ambas reside en que la exceptio non adimpleti contractus supone un incumplimiento total por la otra parte, mientras que la excepcio non rite adimpleti contractus sólo comporta un incumplimiento parcial o defectuoso.

Para Díez Picazo ${ }^{15}$ un cumplimiento inexacto existe en todos los supuestos en que el comportamiento del deudor no se ajusta a los presupuestos, o a las condiciones convenidas, o que se deducen de lo pactado, para entender que hay un pleno pago. Pero estimo que, en cualquier caso, tal incumplimiento debe ser verdadero y debe tener entidad suficiente para justificar el funcionamiento de la exceptio, no bastando un incumplimiento de puntos accesorios del contrato o de escasa transcendencia.

Evidentemente la distinción expuesta no se basa en el derecho positivo, ya que el Código civil, como he indicado, no recoge como tal la excepción, sino en textos doctrinales y en fallos jurisprudenciales. Así por ejemplo la sentencia de 29 de septiembre de $1994^{16}$ la recoge:

«Que centrados en esa forma los términos de la litis, el demandado viene a negar el pago de la cantidad de doscientas cuarenta y seis mil novecientas ochenta y seis (246.986) ptas., y a juzgar por las pruebas que propuso debe entenderse que ejercita la excepción de "non rite adimpleti contractus", o contrato no cumplido adecuadamente. Sobre dicha excepción conviene precisar, que en las relaciones obligatorias de contenido sinalagmático, como es el caso de la presente, el deber de prestación de cada una de las partes funciona como equivalente o como contravalor de la prestación de la otra, de lo que se lleva que la excepción de contrato no cumplido venga admitida por la jurisprudencia, como, asimismo, viene

15 DíEz Picazo, Fundamentos de Derecho Civil Patrimonial, tomo I, Madrid, 1970, p. 686 .

16 Ar. 2.372. 
admitiendo la paralela excepción de cumplimiento irregular, o "non rite adimpleti contractus", debiendo destacarse que en el campo de actuación de esta última excepción no siempre está fundada la negativa a satisfacer la contraprestación por el incumplimiento irregular de la contraparte, por lo que debe acudirse al instituto de la buena fe, lo que hace hayan de ponderarse las circunstancias de cada caso en particular la mayor o menor transcendencia de cada irregularidad, teniendo sentada la jurisprudencia del Tribunal Supremo en Sentencia de 17 abril 1976 que plantea la exceptio "non rite adimpleti contractus", en aras de la buena fe, el demandado no puede eximirse de cumplir con su parte en la contratación, sino en aquello que sea equivalente a la reparación o rectificación reclamada al demandante por su defectuoso comportamiento.»

\section{Excepción y derecho de retención}

Parte de la doctrina (como Oertmann, y Pérez González y Alguer), ha considerado a la excepctio non adimpleti contractus como una modalidad del derecho de retención.

Así se han pronunciado Enneccerus-Lehmann ${ }^{17}$ si bien entienden que ofrece la particularidad de que no puede ser eliminado mediante caución, ya que no está fundado solamente en la seguridad del contracrédito, sino en base a eliminar la injusticia que supone la exigencia de la prestación previa.

La doctrina francesa, en cambio, si bien ve en la exceptio una institución que permite conservar un bien, al menos provisionalmente, a fin de garantizar lo que le es debido en virtud de una contraprestación a una persona; considera sin embargo, que se trata de una institución diferente del derecho de retorno ${ }^{18}$, y así Planiol y Ripert distinguen dos categorías de derecho de retención ${ }^{19}$ :

«Advierten que la «doctrina reciente distingue dos categorías: la retención que se produce en relación de un contrato sinalagmático tiene su fundamento en el principio de la relación entre obligaciones recíprocas y del cumplimiento dando y dando, básico también en la excepción de incumplimiento, aproximándose estrechamente la retención a la excepción.

17 Enneccerus-Lehmann, «Derecho de Obligaciones», en Tratado de Derecho Civil, Barcelona, 1933, Vol. I, p. 165.

18 Véase: Catala, N., «De la nature juridique du droit de rétention», en Rev. Trim. de Droit Civil, 1967, número especial, pp. 15 y ss.; Rodier, notas a, D. 1965, 58 y 78; Weill, Alex, y Terré, FrançoIs, «Les obligations» en Droit Civil, París 1980, p. 546.

19 Planiol y RiPert, Tratado Práctico de Derecho Civil Francés, traducción española, vol. III, n. ${ }^{\circ} 445$. 
Los demás casos se incluyen en otra categoría: se trata de aquéllos en que existe el debitum cum re junctum en el sentido más exacto de la frase, es decir, la conexidad objetiva.»

Ciertamente, un mayor confusionismo se puede dar cuando se trate de un contrato que lleve consigo la transferencia de un bien, sobre todo la compraventa.

Pero la diferencia se acusa más cuando el derecho de retención se aparta de la cosa ajena entregada en virtud de un contrato, por ejemplo de reparación, y ese derecho de retención no equivale para nada a la excepctio non adimpleti contractus.

Tal vez, podríamos concluir diciendo que el derecho de retención es diferente de la excepctio non adimpleti contractus pero que ésta puede llevar consigo incorporado — si su titular decide ejercerla- un derecho de retención sobre el bien objeto de la oposición; pero es de resaltar que según la jurisprudencia francesa la excepción puede aplicarse a cualquier obligación y no solamente a la de entregar un cuerpo cierto o un objeto ${ }^{20}$ sino también al deudor de una obligación de hacer ${ }^{21}$.

Por otro lado, no es necesario que la parte demandada acuda al tribunal para desligarse de su obligación, según una jurisprudencia antigua del Tribunal Supremo ${ }^{22}$, siendo la cuestión del incumplimiento y de quién incurrió en él, ajena al ámbito estricto de la casación ${ }^{23}$; señalando además diversas sentencias que se infringe el artículo 1.124 del Código civil si se acepta una resolución de perjuicios de uno de los contratantes cuando ambos habían faltado a sus recíprocas obligaciones ${ }^{24}$, aun cuando si ambos contratantes lo piden, por respeto al principio de congruencia, la Sala debe acordarlo ${ }^{25}$.

\section{Exceptio y compensación}

También se distingue la exceptio adimpleti contractus de la compensación y, precisamente, por las razones contrarias a las acabadas de exponer respecto del derecho de retención.

$\mathrm{Y}$ es que, mientras la compensación trata de que dos obligaciones diferentes pueden mutuamente contraponerse, la exceptio, por su parte, se

20 Req. 17 de mayo de 1938, D.H. 1938, 419.

21 Soc. 31 de mayo de 1956.

22 S. 29 de diciembre de 1926 y 19 de junio de 1913.

23 S. 12 de diciembre de 1914.

24 SS. 28 de junio de 1893 y 10 de febrero de 1925.

25 S. 4 de junio de 1908. 
circunscribe a las distintas prestaciones que se derivan de un mismo contrato.

La compensación hace referencia, por tanto, a pluralidad de obligaciones, mientras que la exceptio es un método de defensa de quien alega, a sensu contrario, que su contratante ha incumplido la parte que le correspondía en la misma obligación.

El artículo 1.196 del Código civil es suficientemente claro al respecto:

«Para que proceda la compensación, es preciso:

1. ${ }^{\circ}$ Que cada uno de los obligados lo esté principalmente, y sea a la vez acreedor principal del otro.

2. ${ }^{\circ}$ Que ambas deudas consistan en una cantidad de dinero, o, siendo fungibles las cosas debidas, sean de la misma especie y también de la misma calidad, si ésta se hubiese designado.

3. ${ }^{\circ}$ Que las dos deudas estén vencidas.

4. ${ }^{\circ}$ Que sean líquidas y exigibles.

5. ${ }^{\circ}$ Que sobre ninguna de ellas halla retención o contienda promovida por terceras personas y notificada oportunamente al deudor.»

El precepto transcrito evidencia la necesidad de la existencia de obligaciones diversas; y por otro lado hay que tener en cuenta las características de liquidez y exigibilidad contenidas en el artículo 1.196, que no necesitan existir para poder ser alegadas en la exceptio.

Todo ello no empece la concurrencia de ambas, exceptio y compensatio, en una misma situación, y si bien esto es difícil que suceda, no parece que teóricamente, como apunta Espín Cánovas ${ }^{26}$ pueda objetarse nada a su acumulación.

\section{Exceptio y resolución contractual}

La exceptio en sus dos versiones se distingue del derecho de retención (al menos parcialmente); ahora bien, ¿se distingue bien del derecho de resolución? Evidentemente sí: el ejercicio de la exceptio non adimpleti contractus no significa que se lleve a cabo la resolución del mismo, sino que lo único que pone de relieve es la cruzada reciprocidad de las prestaciones bilaterales y recíprocas, y en base a ella, admitir una suspensión de las obligaciones propias fundada en el incumplimiento adverso.

Ahora bien, tal excepción no significa la resolución definitiva del contrato, sino sólo la suspensión de las obligaciones en tanto en cuanto

26 Espín CÁnovas, op. cit., p. 555. 
dure el incumplimiento de la otra parte; y en función de tal incumplimiento se optará, como señala el artículo 1.124 , por la resolución o cumplimiento.

La exceptio puede conjugarse tanto con la resolución como con el incumplimiento; no equivale por tanto al derecho de retención - puede no tener que ejercitarse tal derecho de retención, aun alegando la exceptioy tampoco a la resolución, que puede no tener lugar a pesar de invocar la exceptio non adimpleti contractus.

En definitiva, resolución o incumplimiento estarán en función de la gravedad de la infracción y de la opción que el artículo 1.124 concede al contratante perjudicado, sin olvidar que, de acuerdo con lo que señala el artículo $1.124,2 .^{\circ}$, el perjudicado podrá optar por la resolución, aun después de pedir el cumplimiento, si éste resultara imposible .

En cualquier caso, podemos concluir que si bien la exceptio deriva del artículo 1.124 del Código civil, su ejercicio no supone una rescisión contractual, aunque tampoco la excluye, siendo compatibles con las dos opciones que contiene el artículo 1.124; y en cuanto a los efectos de la exceptio entre los terceros, en principio la exceptio produce sólo efecto entre partes, pero habrá que dejar a salvo al contenido del artículo 1.257 y del propio artículo 1.124 in fine del Código civil.

No obstante, tanto la doctrina ${ }^{27}$ como la jurisprudencia francesa ${ }^{28}$, han optado por aplicar la exceptio non adimpleti contractus sólo en el campo de la suspensión de los contratos, entendiendo que es un beneficio para el acreedor que así no tiene que entregar su contraprestación hasta tanto cumpla la suya el otro contratante, y también para el propio deudor, que de esta forma no ve operar una resolución de pleno derecho del contrato.

\section{Condiciones}

¿Qué condiciones son las que se requieren para poder ejercitar la exceptio non adimpleti contractus? La doctrina ha sido parca al respecto, pudiendo citarse a este respecto a Espín ${ }^{29}$, quien indica como requisitos:

«A) Existencia de un contrato sinalagmático.

B) Falta de cumplimiento de la parte a quien se opone.

C) Alegación no contraria a la buena fe.»

\footnotetext{
WeIll, A. y Terré, F., op. cit., p. 538.

Civ. 29 de junio de 1939, D.H. 1939, 436.

29 EsPín CÁNOvas, op. cit., p. 557.
} 
1. ${ }^{\circ}$ En primer lugar, hace falta la existencia de una obligación sinalagmática que establezca deberes para las dos partes contratantes; sin este requisito previo es lógico que no pueda aplicarse la excepctio glosada, que exige, como su nombre indica, la previa existencia de un contrato.

La sentencia de 29 de julio de $1994^{30}$ señala:

... no consta que la cosa entregada, que no es la pactada, tenga un valor superior al que ya ha abonado por ella la demandada hoy recurrente la cual puede desde luego abstenerse de cumplir con su prestación mientras la vendedora no cumpla con la suya pues, como ya quedó dicho en las Sentencias civiles de esta Sala de 20 octubre 1989, 19 abril 1.991 y 13 julio 1993; en la penal de 28 septiembre 1993 y en la Civil de 12 marzo 1994, los contratos bilaterales o con obligaciones recíprocas, como lo es la relación jurídica del caso, vienen informados por el principio del cumplimiento simultáneo, atendiendo a la conexión e interdependencia existente entre las obligaciones de las partes —el sinalagma—, que no admite la separación temporal entre las dos prestaciones en juego, salvo que así se haya convenido o resulte de la misma naturaleza del contrato o de los usos del tráfico, lo cual tiene su reflejo en el derecho positivo en los artículos 1.466 y 1.500 del Código civil, para el contrato de compraventa, pero es de general aplicación para todas las relaciones sinalagmáticas, dando lugar a las excepciones del contrato no cumplido y del cumplimiento inexacto, en cuya virtud, cada parte contratante puede oponerse a desarrollar su prestación si la otra no ha dado efectividad a la suya o no ofrece cumplirla simultáneamente en la ejecución denominada «mano a mano», ejerciendo el derecho a abstenerse provisionalmente de cumplir en tanto el otro sujeto no realice su contraprestación correctamente.

2. ${ }^{\circ}$ Es necesario que las obligaciones no solamente sean mutuas, sino que nazcan del mismo contrato, ya que no cabría oponer al acreedor contractual una prestación distinta que naciera por título jurídico diferente. La exceptio non adimpleti contractus se refiere siempre a las obligaciones nacidas del propio convenio, y no a la compensación, que por causas diferentes pudiera existir entre dos personas.

Así lo ha admitido el Tribunal Supremo ${ }^{31}$ y también la jurisprudencia francesa, al precisar que es necesario que las dos obligaciones recíprocas deriven de un mismo contrato ${ }^{32}$, aunque la antigua doctrina francesa mantenga la opinión contraria recogida por Espín Cánovas ${ }^{33}$ :

30 Ar. 1.589.

31 S. 29 de julio de 1994, Ar. 1.589.

32 Req. 17 de mayo de 1.938, D.H. 1938, 419.

33 Espín CÁnovas, op. cit., p. 557. Aunque el mismo Espín reconoce la oposición de parte de la doctrina francesa encabezada por Capitant a tal tesis. 
«En este sentido Cassin propone aplicarla a los siguientes casos:

1. A las relaciones nacidas de la anulabilidad de un contrato sinalagmático ya ejecutado.

2. ${ }^{\circ}$ A los contratos unilaterales imperfectos

3. ${ }^{\circ}$ A las relaciones sinalagmáticas incompletas y a los cuasi contratos.

4. ${ }^{\circ}$ A lo que llama, relaciones sinalagmáticas creadas por la ley o bajo la autoridad de la ley (expropiación por causa de utilidad pública, retractos, tutela, etc.).»

3. ${ }^{\circ}$ Hace falta que las prestaciones no estén cumplidas, ya que de estarlas, la exceptio no tendría objeto ni finalidad alguna.

Esa es la interpretación del Tribunal Supremo en su sentencia de 6 de julio de $1993^{34}$, la cual precisa:

«... 2. ${ }^{\mathrm{a}}$ La alegación del supuesto incumplimiento contractual por una de las partes ("exceptio non adimpleti contractus"), que sería plenamente adecuada y procedente si el objeto litigioso versara sobre la pretensión de cumplimiento de dicho contrato, deducida por la parte supuestamente incumplidora, resulta totalmente extemporánea e inoportuna, cuando el contrato ya quedó cumplido y extinguido por expiración de su vigencia temporal y lo único que pretende una de las partes es la liquidación de las cuentas pendientes entre ellas, como consecuencia del expresado cumplimiento.»

4. ${ }^{\circ}$ Debe de tratarse de incumplimiento verdadero, ya que si hubiera un aplazamiento de pago, la otra parte contratante no podría alegar tal aplazamiento, contractualmente previsto, para incumplir sus propias obligaciones ${ }^{35}$.

5. ${ }^{\circ} \mathrm{El}$ incumplimiento debe tener una cierta importancia para poder a su vez suspender la contraprestación ${ }^{36}$.

6. ${ }^{\circ}$ Finalmente debe haber una proporcionalidad entre la actuación de uno de los contratantes y la aplicación de la exceptio, dado que la actuación debe ir presidida por las reglas de la buena $\mathrm{fe}^{37}$.

Espín ${ }^{38}$, siguiendo a De Page, analiza los supuestos en que se faltaría a este requisito:

«1. ${ }^{\circ}$ La excepción no puede ser invocada más que en caso de falta grave a las obligaciones principales del contrato; no en caso de faltar a obligaciones secundarias.

34 Ar. 5.797.

35 SS. 30 de abril de 1981, Ar. 1.784 y 6 de julio de 1989, Ar. 5.404.

36 S. A.P. Jaén de 15 de abril de 1993, Ar. Civ. 463.

37 En cuanto a jurisprudencia francesa, Civil 1re 23 de octubre de 1963, 364, 33; Civil 5 de marzo de 1974, Sem. Jur. 1974, II, 17.707: Civil 1re 27 de mayo de 1961, Bull. Crim. 1961, I, n. ${ }^{\circ} 264$.

38 Espín CÁnovas, op. cit., p. 566. 
2. ${ }^{\circ}$ La excepción no puede ser alegada cuando el que la alega ha motivado el incumplimiento de la otra parte o ha faltado él mismo a sus obligaciones.

3. ${ }^{\circ}$ En general, debe rechazarse también la excepción, cuando al que se le opone, puede invocar una causa legítima para no cumplir.»

Es perfectamente aplicable el artículo 7 del Código civil tanto en su llamamiento a la buena fe, que contiene el $n .^{\circ} 1 .^{\circ}$, como en la interdicción del abuso de derecho recogida en su n. ${ }^{\circ} 2 .{ }^{\circ}$, así como la prohibición del fraude de ley recogida en el artículo $6-4 .^{\circ}$.

Tal conjunto de normas deberá tenerlas en cuenta el juzgador para rechazar aquellos supuestos de excepción que constituyan una colisión con la buena fe y supongan un abuso de derecho: precisamente una institución como la comentada, fundada en principios de justicia y equidad, debe ser la más lejana a admitir actos que se opongan a aquéllas.

Notemos sin embargo que no hace falta siempre un incumplimiento total, porque el parcial es el que dará origen a la exceptio non rite adimpleti contractus ${ }^{39}$. En tales circunstancias hay que atender a la finalidad de los contratantes y, concretamente, a si han querido hacer del mismo un todo indivisible para aceptar o no que, por un incumplimiento parcial, se resuelva la totalidad del contrato ${ }^{40}$.

En cambio, no participo totalmente de la opinión de Enneccerus de que el demandante tenga que desvirtuar la excepción de la contraexcepción (réplica) que él tiene que probar: entre el derecho a la exceptio y el contenido concreto de él, el primero de ellos es una cuestión jurídica exenta de prueba, mientras que en cuanto a la alegación sobre si la otra parte ha incumplido o ha cumplido defectuosamente un contrato, me remito a lo que expongo en el apartado siguiente.

Lógicamente, en los contratos y obligaciones recíprocas, la posibilidad de resolución afecta nada más que al período a partir del cual uno de los contratantes ha incumplido sus obligaciones ${ }^{41}$.

\section{Ejercicio de la exceptio}

Dándose los requisitos para que la exceptio pueda aplicarse, vamos a ver sumariamente cómo ésta habrá de ejercitarse.

\footnotetext{
39 En sentido contrario, ENNECCERUS-LEHMANN (op. cit., p. 166) con la matización de atender prioritariamente a la buena fe de quien lo alegue.

40 Civ. 1re. 3 de noviembre de 1983, Bull. Civ. I, n. 252.

41 Civ. 3e 28 de enero de 1975. Bull. Civ. III, n. ${ }^{\circ} 33$.
} 
Si hubiera acuerdo entre ambas partes, el ejercicio de la exceptio non adimpleti contractus podía ser mediante un nuevo convenio entre ambos.

No existiendo tal acuerdo, que será lo más probable, se plantea a su vez el ejercicio de la excepción judicial o extrajudicial.

Como antes he indicado, no hace falta el ejercicio judicial, pudiendo simplemente quien desee beneficiarse de ella, acogerse a la misma mediante la indicación, en tal sentido, dirigida a la otra parte.

Ni siquiera hace falta que tal indicación sea de forma fehaciente, si bien tal medio será conveniente como demostración de la declaración de voluntad.

Si la otra parte ha iniciado el procedimiento judicial será entonces necesario ejercitar la exceptio dentro del procedimiento, en el cual tendrá el carácter de verdadera excepción defensiva.

En definitiva, si es el demandado quien se acoge a la exceptio, éste la ejercitará judicialmente, mientras que si toma la iniciativa quien con la misma pretende beneficiarse, podrá optar entre la vía extrajudicial y la judicial.

Dentro del procedimiento judicial será al demandado al que le corresponda la carga de la prueba, como antes he indicado, de los hechos en que basa el incumplimiento de la contraparte, por imperativo de lo dispuesto en el artículo 1.214 del Código civil. No comparto la opinión de Espín Cánovas ${ }^{42}$, según el cual al demandado le bastará alegar la excepción de incumplimiento para hacer recaer la prueba sobre el actor. Sobre el objeto de la demostración del incumplimiento del actor habría que matizar:

a) La questio iuris de la exceptio no está sujeta a prueba.

b) Si se trata de un incumplimiento total, es decir de no cumplimiento por la otra parte, efectivamente será el actor quien deba demostrar que ha cumplido su prestación.

c) Si se trata de un incumplimiento parcial o defectuoso, la carga de la prueba, a tenor del artículo 1.214 del Código civil, recaerá en el excepiens.

En cualquier caso, hay que tener en cuenta que tales reglas no son matemáticas y que es de sobra conocida la crítica que la doctrina procesal moderna ha hecho al principio de distribución de la carga de la prueba y, como corolario, que en cualquier caso cada parte tratará de demostrar aquellos hechos que le beneficien.

42 Espín CÁnovas, op. cit., p. 580. 
La exceptio puede no ser un método de defensa definitivo ya que si la parte incumplidora efectuase su prestación, la alegación de la contraria decaería, y la exceptio no tendría razón de ser, a salvo por supuesto, de que el cumplimiento sea efectuado dentro del plazo estipulado y con las condiciones prefijadas.

En cuanto a la posible mora como consecuencia del ejercicio de la exceptio señala Espín Cánovas ${ }^{43}$ :

«El que opone la excepción no incurre en mora, ya que ésta en las obligaciones recíprocas no se produce para una parte mientras la otra no cumple (art. 1.100, últ. ap.), pero lo que no cabe desconocer es que las obligaciones desde el incumplimiento temporal o retraso, prolongan la situación en que se encontraban las partes creando un tiempo intermedio entre la exigibilidad de las recíprocas obligaciones y su cumplimiento ulterior, que no es calificable de mora, pero que puede plantear algunas cuestiones, como la responsabilidad por la custodia de las cosas que deban ser entregadas, los riesgos por el perecimiento fortuito, etc.

En ese período intermedio, no calificable de mora, ¿se produce alguna modificación en las respectivas situaciones de las partes antes del vencimiento de las obligaciones o simplemente se prolonga esa situación de recíprocos deudores de obligaciones aún no exigibles?

El deudor incurso en mora queda sujeto a una agravación de su responsabilidad normal, como lo demuestra su responsabilidad por los casos fortuitos expresamente sancionada en nuestro Código (art. 1.096, ap. 3), por lo que al excluirse la situación de mora durante el tiempo en que produzca sus efectos la excepción, deberá excluirse congruentemente esa agravación de la responsabilidad.

[...]

Creemos más adecuado a la naturaleza de las obligaciones que nacen equilibradas en el contrato bilateral, mantener la misma situación en que se encontraban las partes llegado el momento del cumplimiento simultáneo, no cumplido por ninguna. En realidad el que una de las partes se adelante indebidamente a reclamar motivando la fundada alegación de la excepción por el demandado, no varía en su favor la situación de cumplimiento diferido en que se encuentra.

Conforme a este principio de mantenimiento de la misma situación contractual anterior el vencimiento simultáneo de las obligaciones recíprocas, creemos deberán resolverse los problemas que puedan surgir, además de los indicados del perecimiento fortuito y deber de diligencia en la custodia (por ejemplo, gastos hechos en la conservación de la cosa, producción de frutos).»

43 Espín CÁnovas, op. cit., pp. 572 y ss. 


\section{La exceptio non adimpleti contractus y la letra de cambio}

¿Es compatible la exceptio comentada con la emisión de cambiales para el pago de la prestación contractual?

En primer lugar habría que distinguir si la relación es entre librador y librado o ha habido ulteriores transmisiones cambiarias del efecto.

Si la relación no es sólo ente librador y librado, es claro que la cambial se convierte en un título abstracto, y contra ella no podrá alegar en modo alguno el obligado cambiario las excepciones causales de acuerdo con el artículo 67-6 de la Ley Cambiaria y del Cheque.

Si la relación es entre librador y librado, entiendo que la exceptio podría ser esgrimida. No obstante, hay que tener en cuenta que la jurisprudencia ha matizado tal admisibilidad en el sentido de que el incumplimiento parcial no cabe oponerlo al acreedor cambiario, aunque fuera la relación entre librador y librado.

La sentencia del Tribunal Supremo de 13 de octubre de $1994^{44}$ señala:

«La excepción de contrato no cumplido "exceptio non adimpleti contractus", que, en los contratos sinalagmáticos, puede oponerse una de las partes contratantes frente a la otra, que le exige el cumplimiento de la obligación contractual, invocando que la parte reclamante tampoco ha cumplido con su propia obligación contractual (No formulada en el CCiv. con carácter general aunque se hacen aplicaciones concretas respecto a la venta, en los artículos $1.466,1.500$ y 1.505 , a la permuta, en el artículo 1.539 , a restitución procedente por causa de nulidad o anulabilidad del contrato, en el artículo 1.308, y a la rescisión, en el artículo 1.295; pudiendo inducirse de los artículos 1.124 y 1.100 apartado último; y habiéndose reconocido por una constante y reiterada doctrina jurisprudencial), puede oponerse en el juicio ejecutivo instado en base a letras de cambio, al amparo de lo dispuesto en la primera frase del párrafo primero del artículo 67 de la Ley Cambiaria 19/1985, de 16 julio ("El deudor cambiario podrá oponer al tenedor de la letra las excepciones basadas en sus relaciones personales con él"). Pero, a pesar de incumbirle la carga de la prueba, no logró acreditar el ejecutado ese incumplimiento contractual por parte del ejecutante. Propone como testigos a quienes tienen una clara relación de dependencia laboral respecto del ejecutado, y en cualquier caso el incumplimiento se referiría a la prestación de servicios cuando las letras cumplen la función de pago del precio por la entrega de cosas.»

Y la sentencia de 24 de octubre de $1994^{45}$ manifiesta:

44 Ar. 2.157. En idéntico sentido las sentencias de 27 de octubre de 1994, Ar. 2.410 y 24 de noviembre de 1994, Ar. 2.036 .

45 Ar. 2.411. 
«La razón del rechazo de tal excepción se encuentra en que la valoración de si ha existido o no cumplimiento defectuoso, parcial o tardío exige un complejo análisis de las relaciones "inter partes" y con un entramado de pruebas que exceden de los estrechos márgenes de un juicio sumario como el ejecutivo, por lo que debe reservarse su examen para el juicio declarativo. Ello no ocurre, y por lo tanto la excepción se admite, cuando se trata de un incumplimiento absoluto y total o falta de cumplimiento ("exceptio non adimpleti contractus") o cuando el defecto alegado de la prestación sea de tal entidad que haga inservible la cosa para su fin o destino económico, frustrando así la función económica y jurídica del contrato y las expectativas del otro contratante, lo que entonces equivale a un incumplimiento total y propio.»

La sentencia de la Audiencia Provincial de Jaén de 15 de abril de $1993^{46}$, señala que tal excepción puede oponerse en juicio ejecutivo al amparo del artículo 67 de la Ley Cambiaria y del Cheque de 16 de julio de 1985 cuando el juicio se dilucida entre librador y librado; pero continúa diciendo que un incumplimiento accesorio e impropio, que es constitutivo de la exceptio non rite adimpleti contractus, en ningún caso tiene la virtualidad de hacer ineficaz la acción ejecutiva esgrimida, citando las sentencias del Tribunal Supremo de 10 de octubre de 1970, 10 de diciembre de 1982, 10 de diciembre de 1983 y 15 de septiembre de 1983 .

La sentencia de la Audiencia Provincial de Granada de 27 de julio de $1993^{47}$, indica que:

«Tal y como ya tiene declarado esta Sección (S. 11-3-1991 que cita la de 1-10-1980 de la AP de Murcia, entre otras), la excepción de plus-petición no tiene en el juicio ejecutivo basado en letra de cambio, más que dos posibilidades de aplicación, relativa una a los gastos ejecutoriados del protesto, cuando la letra de cambio contiene la cláusula «sin gastos»; y la otra el supuesto del pago parcial de la letra, que no ha sido tenido en cuenta al interponer la demanda ejecutiva por la que vuelve a reclamarse un pago ya hecho; todos los demás casos de deudas pendientes, etc., podrán dar lugar a otras excepciones, pero nunca podrán alegarse al amparo de la pluspetición. Debe desestimarse la excepción, cuando frente al impago de diversas letras de cambio se aduce el saldo resultante tras diversos pagos efectuados por la demandada en distintas operaciones mercantiles habidas entre las partes, pues esta complejidad desborda el contenido del juicio ejecutivo, so pena de convertirlo en un plenario, lo que no es posible dada su naturaleza sumaria, cabiendo decir, en el caso presente, y para mayor abundamiento que tal y como se hace constar en la sentencia de instancia, los pagos son posteriores al nacimiento de la deuda que dio origen a las cambiales, y que por lo expuesto no puede así por las buenas imputarse a dicha obligación.»

\footnotetext{
46 Ar. Civil 463.

47 Ar. Civil 1.643.
} 
La sentencia de 5 de diciembre de 1994 de la Audiencia de Salaman$\mathrm{ca}^{48}$, manifiesta:

«La anterior doctrina se ha de completar ahora diferenciando a los efectos que nos ocupan entre incumplimiento contractual pleno o incumplimiento propiamente dicho, e incumplimiento parcial o incumplimiento defectuoso o irregular porque, como recuerdan, entre otras, las SS. AP, de Madrid de 13 de julio 1993 y de Granada de 28 septiembre 1993, el criterio uniforme es el de admitir la excepción de falta de provisión de fondos en el primer supuesto, esto es, el incumplimiento total, mientras que no considera admisible en el segundo, entendiéndose que no cabe la excepción cuando consta que el librador de los efectos cumplió sustancialmente lo convenido en el contrato subyacente.»

Como conclusión, la exceptio no es aplicable a la ley cambiaria cuando la relación no es exclusivamente entre librador y librado; y si la relación es entre ambos, sería oponible la exceptio non adimpleti contratus y no la exceptio non rite adimpleti contractus.

No hay que confundir el incumplimiento con determinadas hipótesis que tienen un tratamiento específico, como pueden ser la acción en reclamación de vicios de construcción (ex artículo 1.591 Código civil) y que no dará origen a la oposición, con fundamento, de la excepción comentada.

En las breves páginas precedentes he tratado de dar una visión global, y fundamentalmente jurisprudencial, de una institución que, aunque no recogida en la Ley, tiene una importante operatividad en la praxis jurídica cotidiana. 